\title{
DE LOS DERECHOS POLÍTICOS A LAS LISTAS DE LAVANDERIA. LOS PROBLEMAS DEL CASO "CRUZ-COKE"
}

\author{
FROM POLITICAL RIGHTS TO LAUNDRY LISTS. \\ The PROBlems of CRUZ-CoKe's CASE \\ DE LA POLITIQUE DES DROITS AU LISTES DE BLANCHISSERIE. \\ LeS PROBlèmes de l'AFFAIRE “CRUZ-CoKE” \\ José Francisco García G. ${ }^{*}$, Sergio Verdugo R. ${ }^{*}$
}

"[The rule of law] to the extent that the concept is intended to mean that judges apply only pre-existing law, can never exist. Judges often make rules for decision of future cases and a re, therefore, making law [...], judges must always deny that they make law [...] Courts and judges always lie. Lying is the nature of the judicial activity".

Martin Shapiro ${ }^{1}$

\section{INTRODUCCIÓN}

En septiembre de este año, el Tribunal Calificador de Elecciones (TRICEL) resolvió acoger los reclamos presentados contra la inscripción de la candidatura al Senado de Luciano Cruz-Coke (Evópoli), quien integraba la lista de candidatos de la "Alianza" que perseguía la obtención de un escaño en la circunscripción de

\footnotetext{
* Licenciado en Derecho por la Pontificia Universidad Católica de Chile. Magíster en Derecho Público por la misma cada de estudios. Doctor y Master en Derecho por la Universidad de Chicago. Coordinador de Políticas Públicas Libertad y Desarrollo. Profesor de Derecho Constitucional de la Pontificia Universidad Católica de Chile. Correo electrónico: jfgarcia@uc.cl.

** Licenciado en Ciencias Jurídicas por la Universidad del Desarrollo. Máster en Derecho por la Universidad de California, Berkeley. Magíster en Derecho Público por la Pontificia Universidad Católica de Chile. Profesor de Derecho Constitucional e Investigador del Centro de Justicia Constitucional de la Universidad del Desarrollo. Correo electrónico: sverdugor@udd.cl.

Agradecemos la colaboración de Jennifer Quintana, ayudante de investigación de la Facultad de Derecho de la Universidad del Desarrollo, en la revisión final de las referencias bibliográficas.

${ }^{1}$ Shapiro, Martin (1994). "Judges as Liars". Harvard Journal of Law and Public Policy, Vol. 17, pp. 155156.
} 
Antofagasta 2 . La discusión central del caso residía en la supuesta calidad de "ministro de Estado" del candidato Cruz-Coke, la que le habría impedido presentarse como candidato por no haber renunciado en el plazo constitucional respectivo.

Era la primera vez que el TRICEL resolvía el problema relativo al "rango de ministro" de quien encabeza el Consejo Nacional de la Cultura y las Artes (CNCA), y lo hizo de una manera especialmente impactante para el escenario electoral que se vivía en ese momento. Atendida la lista cerrada que implica el sistema binominal de elecciones de parlamentarios, y el vencimiento del plazo para la inscripción de las candidaturas, la "Alianza" se quedó con un solo candidato en su lista (de un máximo de dos), viéndose en una posición desmedrada respecto de su competidor político más importante: la "Nueva Mayoría" (pacto electoral que une a la Concertación y al Partido Comunista). Los efectos políticos de lo anterior son relevantes: (1) probablemente la Nueva Mayoría doblará en número de votos a la "Alianza", obteniendo un senador más en la circunscripción de Antofagasta y alterando el juego de las facciones al interior del Senado ${ }^{3}$; (2) se reduce la oferta electoral parlamentaria, pudiendo los electores de la circunscripción respectiva sólo votar por las que permanecen, lo que es particularmente dañino para el "derecho a elegir" de los electores simpatizantes de la centro-derecha; (3) y se impide el ejercicio del "derecho a presentarse a cargos de elección popular" de un ciudadano.

Ninguna de estas circunstancias fue relevante para el TRICEL (tampoco para el voto de minoría del ministro Valdés) el que prefirió seguir una interpretación extensiva de las inhabilidades establecidas en la Constitución, ignorando evaluar los efectos político-constitucionales de su decisión. Un caso como éste plantea varias interrogantes que serían interesantes de analizar para el estudio del poder de los jueces, especialmente considerando la ausencia de sentencias judiciales precedentes y un evidente problema jurídico que conduce a la posibilidad de que existan diversas interpretaciones alternativas para resolver la pregunta jurídica sometida a su decisión. ¿Debe el TRICEL ser deferente con los derechos políticos? ¿Es la mejor respuesta democrática posible un estándar constitucionalmente válido para solucionar este tipo de casos? ¿Pueden las respuestas jurídico-positivas formalistas dar una respuesta satisfactoria a los problemas electorales que sufre el sistema con este tipo de decisiones? ¿Deben los tribunales ignorar la existencia de

\footnotetext{
${ }^{2}$ Sentencia Tribunal Calificador de Elecciones, "Partido Socialista de Chile y Consejo Directivo del Servicio Electoral”, Rol No 110-2013, 12 de septiembre de 2013 (acción de reclamación por inhabilidad). Disponible en: <http://www.tribunalcalificador.cl/informacioncausas/Tramitacin\%20de\%20Causas/110-2013\%20 35.-\%20Sentencia\%20\%2012-09-2013.pdf>. [consulta: 17 octubre 2013].

${ }^{3}$ Esta probabilidad de doblaje se alimenta también por la existencia de un senador en ejercicio que se presenta como candidato independiente (Carlos Cantero), quien perteneció a Renovación Nacional y decidió presentarse nuevamente para competir contra la "Alianza por Chile" en una lista separada. El posible apoyo de numerosos votos de centro-derecha para este candidato (en desmedro de los votos que necesita la "Alianza por Chile") se suma a la ausencia de un compañero de lista para el candidato de la Unión Demócrata Independiente, quien debido a la decisión del TRICEL debe enfrentar de manera solitaria la difícil tarea de sumar los votos necesarios para impedir el doblaje de la "Nueva Mayoría".
} 
valores democráticos profundos cuando resuelven un caso sobre la base de reglas interpretadas de manera dudosa?

En este trabajo, analizaremos críticamente la sentencia del TRICEL, argumentando que ella elige resolver una causa sobre la base de una interpretación dudosa donde los principios constitucionales que sustentan nuestra democracia pudieron haber aconsejado una mejor respuesta para nuestro sistema electoral. Sostendremos que cuando los jueces se ven enfrentados a este tipo de problemas debido a la inexistencia de una regla jurídica precisa (la Constitución no prevé de manera explícita la solución a este caso), las alternativas interpretativas deben ser especialmente deferentes, y la argumentación debe fundarse en los valores de nuestra democracia constitucional. Independientemente del resultado final de la sentencia, lo que parece especialmente criticable es la argumentación que la misma desarrolla. De esta manera, en este trabajo sostendremos que una interpretación judicial como la que efectivamente se entregó, podría ser valiosa si se fundara en el tipo de razones correctas. Sin embargo, cuando el TRICEL evita pronunciarse sobre las mismas entregando motivos cuestionables y ajenos a su propia jurisprudencia restrictiva en materia de inhabilidades, no sólo reduce el ámbito de la discusión a aquellos asuntos menos importantes, sino que también entrega una señal dañina sobre el rol de los jueces en este tipo de casos, generando además un escenario desfavorable para la seguridad jurídica.

En la sección 1, resumiremos brevemente el problema jurídico presentado y la tarea que enfrentaba el TRICEL, poniendo énfasis en el tipo de discusión de que se trata. En la sección 2, criticaremos la argumentación de la sentencia, la que estimamos débil. Sostendremos que, incluso en el supuesto de que la misma tuviera un resultado correcto (lo que es altamente discutible), creemos que ella está lejos del mejor razonamiento posible para la doctrina constitucional que dice defender, ya que ella carece de consideraciones basadas en los valores constitucionales relevantes como sistema. En la sección 3, argumentaremos que la sentencia trae costos importantes para la justicia del caso concreto, alterando máximas como la buena fe y la certeza jurídica, y explicaremos que es especialmente importante que las reglas electorales operen con la debida estabilidad, objetividad e imparcialidad en la solución de los casos concretos, lo que demanda que los cambios normativos entren en vigencia para elecciones futuras, y no para procesos electorales en curso. Finalmente, concluiremos infiriendo algunas lecciones que este caso nos deja para el futuro.

\section{El problema jurídico del caso Cruz-Coke Y SU CONTEXTO}

En nuestro país, existen algunos cargos públicos que reciben el trato de "Ministro" sin serlo, como ocurre con el Presidente del CNCA y la Directora del Servicio Nacional de la Mujer ("SERNAM"). En el caso del presidente del 
CNCA, la ley dispone que, "tendrá el rango de Ministro de Estado y será el jefe superior del servicio" (artículo 5, No 1 de la Ley No 19.891). El problema no sólo es uno de forma, de trato o protocolo, sino de fondo: se trata de jefes de servicio que simplemente carecen de varias de las potestades de las que sí gozan los "Ministros de Estado" 4 .

Cabe constatar que el constituyente no tuvo a la vista la solución para este tipo de casos, cuyo conflicto nace debido a la creación legislativa de instituciones híbridas, lo que estimula a los abogados a discutir su naturaleza bajo argumentos que escapan a las propias normas constitucionales. En efecto, los razonamientos de las partes descansan en una interpretación de la naturaleza de la figura creada por la ley, para acomodarla a la categoría constitucional de "ministro" o para rechazarla.

Y, como puede entenderse de los argumentos de las partes, así como existen similitudes entre estos jefes de servicio con los ministros respectivos, también existen diferencias, lo que ha dado lugar a una discusión relativa y aparentemente equilibrada, que se demuestra con la existencia de razones jurídicas interesadas para ambas partes 5 . Así, por ejemplo, si por un lado se argumentaba que CruzCoke no era ministro porque no integraba el orden de precedencia de éstos ${ }^{6}$, por el otro se argumentaba que si era ministro porque tenía la facultad para intervenir en el debate parlamentario, cuestión reservada a los ministros (artículo 37 de la

\footnotetext{
${ }^{4}$ En el caso del CNCA, se ha argumentado que no se encuentra en la Ley Orgánica de Ministerios; es un servicio público autónomo, descentralizado y colegiado, cuyos actos deberán realizarse a través del Ministerio de Educación; el decreto que refundió, coordinó y sistematizó las reformas a la Constitución de 2005 -dejando como resultado la denominada "Constitución de Lagos"-, lleva todas las firmas de los Ministros del Estado, no incluyendo la del Presidente del CNCA; entre otros.

${ }^{5}$ Muchas de estas razones fueron dadas a conocer mediante diversas columnas de opinión de académicos de diferentes sectores. Por ejemplo, ver la opinión del profesor Pablo Contreras, defendiendo la posición de la "Nueva Mayoría”: Contreras VÁsquez, Pablo (2013). "El Ministro Cruz Coke y la 'letra chica' en democracia". Centro de Investigación Periodística, columna de opinión, 22 de abril. Disponible en: <http:// ciperchile.cl/2013/04/22/el-ministro-cruz-coke-y-la-\%E2\%80\%9Cletra-chica\%E2\%80\%9D-en-democracia/> [consulta: 8 octubre 2013]. Ver también, por ejemplo, la opinión del profesor José Francisco García, defendiendo la pretensión jurídica del candidato de la "Alianza por Chile": García, José Francisco (2013). "Sentencia Cruz Coke: Realismo mágico jurídico". La Tercera, 23 de septiembre. Disponible en: <http:// voces.latercera.com/2013/09/23/jose-francisco-garcia/sentencia-cruz-coke-realismo-magico-juridico/> [consulta: 8 octubre 2013]. Otro ejemplo interesante lo representa la postura de Axel Buchheister, quien si bien simpatiza con los intereses de la "Alianza", criticó tempranamente la decisión política de la candidatura por estimarla riesgosa: BuChHeister, Axel (2013). "Candidatura senatorial riesgosa”. La Tercera, 4 de agosto. Disponible en: <http://voces.latercera.com/2013/08/04/axel-buchheister/candidatura-senatorial-riesgosa/> [consulta: 8 octubre 2013]. Especialmente interesante nos parecen los originales comentarios del profesor Eduardo Cordero, entregados en una columna de opinión en: Cordero QuinzaCARA, Eduardo (2013). "El "rango" de ministros de Estado de los jefes de servicio". El Mercurio Legal, 7 de agosto. Disponible en: <http://www.guerrero.cl/el-rango-de-ministro-de-estado-de-los-jefes-de-servicio/prontus_guerrero/201308-08/095810.html> [consulta: 17 octubre 2013].

${ }^{6}$ Ello es relevante para los casos de subrogación y vacancia, de acuerdo a lo establecido en el Decreto con Fuerza de Ley No 7.912, Decreto que organiza las Secretarías del Estado, Diario Oficial, 5 de diciembre de 1927.
} 
Constitución). Argumentos de este tipo abundaron en ambas posiciones ${ }^{7}$. En consecuencia, mientras una de las partes intentó persuadir al TRICEL con el razonamiento de que, si existen similitudes, entonces el principio de la realidad dice que debe ser considerado como ministro de Estado; la otra sostenía lo opuesto, esto es, que como existen diferencias, entonces la naturaleza de su función debe ser considerada de manera diversa y, desde luego, el jefe de servicio no debía ser tratado como ministro.

En este escenario, y como puede fácilmente observarse, es posible construir argumentos interesados relativamente persuasivos, lo que da un espacio importante para que los abogados defiendan de manera creativa sus propias teorías constitucionales. Por ello, es fácil predecir cuál sería la posición de los abogados de las partes (lo que también hace comprensible la judicialización de esta causa) pero no la de los jueces, con lo que era bastante sencillo adelantar que la tarea del TRICEL no sería compartida por todos y que su interpretación siempre estaría sometida a una exégesis alternativa, lo que se demuestra en la existencia de un muy bien argumentado (aunque solitario) voto disidente ${ }^{8}$.

Si bien nuestra posición jurídico-constitucional simpatiza con el argumento disidente y no creemos que las mejores posiciones de ambas partes pudieran anularse recíprocamente (como debería ser si el problema se tratara únicamente enfrentando ambas posiciones con razones tipo lista de lavandería), la manera en que el debate fue presentado públicamente lleva razonablemente a creer que la controversia no tendría una solución predecible a priori. Ello se debe fundamentalmente a dos razones:

En primer lugar (i), a que el caso suscitó mucho interés político, donde partidos con influencia y presencia mediática interesados en el posible doblaje de la "Nueva Mayoría”, generaron un clima de incertidumbre, donde no era fácil orientar políticamente la posición de los jueces, cómo sí ha ocurrido en otros casos de inhabilidad parlamentaria en manos del Tribunal Constitucional, donde la ausencia de un clima especialmente fuerte que presione por la inhabilidad parlamentaria permitió que dicho Tribunal rechazara los requerimientos de inhabilidad con relativa comodidad (lo que se demuestra en las sólidas mayorías judiciales conseguidas) ${ }^{9}$.

\footnotetext{
${ }^{7}$ El listado es bastante grande. Por ejemplo, a él se suma la discusión sobre la remuneración del "ministro", su juramento de ministro, la (im)posibilidad de que sea interpelado o acusado constitucionalmente, la (in) existencia de Secretarías Regionales Ministeriales, su trato (in)directo e (in)mediato con el Presidente de la República y con el Ministro de Educación, su (in)capacidad para firmar decretos supremos, de su integración en el gabinete de ministros, entre muchos otros aspectos relevantes que estimulaban los argumentos de ambas partes.

${ }^{8}$ Ver el voto particular del ministro Patricio Valdés, en sentencia del Tribunal Calificador de Elecciones, 12 septiembre 2013.

${ }^{9}$ Ver, por ejemplo, los casos de las inhabilidades de los senadores Navarro y Von Baer y, también el requerimiento en contra del nombramiento de Carolina Tohá como ministra. Ver en sentencia Tribunal Constitucional, Rol No 970, 7 de octubre de 2008 (requerimiento de doce diputados para que se declare
} 
En segundo lugar (ii), la solución del caso era relativamente impredecible debido a que no existe una respuesta jurídica directa y clara que resuelva el problema. En efecto, la Constitución no define con precisión lo que debe entenderse por ministro de Estado ${ }^{10}$, por lo que ninguna de las partes pudo recurrir a una regla explícita, salvo tal vez por la cita a la jurisprudencia administrativa de la Contraloría ${ }^{11}$ y la opinión del Tribunal Constitucional ${ }^{12}$. Por esta razón, puede sostenerse que, pese a que la solución judicial era relativamente impredecible, el candidato actuó siguiendo

la cesación en el cargo del senador Alejandro Navarro Brain, por haber incurrido en las causales de inhabilidad previstas en el artículo 60, incisos cuarto y quinto, de la Carta Fundamental). Disponible en: <http://www.tribunalconstitucional.cl/wp/expedientes> [consulta: 17 octubre 2013]; sentencia Tribunal Constitucional, Rol No 1357, 9 de julio de 2009 (requerimiento para que se declare la inhabilidad constitucional de la diputada Carolina Tohá Morales para ejercer el cargo de Ministro de Estado y la elección de don Felipe Harboe Bascunán como diputado reemplazante). Disponible en: <www.tribunalconstitucional. cl> [consulta: 17 octubre 2013]; sentencia Tribunal Constitucional, Rol No 2087, 29 de diciembre de 2011(requerimiento formulado por diversos parlamentarios para que se declare la inhabilidad de Ena Von Baer Jahn para desempeñar la función parlamentaria de senadora de la República). Disponible en: <www. tribunalconstitucional.cl> [consulta: 17 octubre 2013].

En todos estos casos el Tribunal Constitucional se vio enfrentado a un interés partidista relativamente transversal que permitiera el nombramiento o conducta reprochados. Ello se evidencia por el tipo de requirente que participó, el que siendo minoritario y no representativo de su sector, pudo ser fácilmente rechazado por mayorías sólidas (sino la unanimidad) al interior del Tribunal, el que prefirió sostener interpretaciones deferentes con los intereses políticos en juego. Como puede advertirse, esta situación no sucedió en el caso que comentamos, donde en TRICEL se enfrentó a una posición hegemónica al interior de la "Nueva Mayoría" en el sentido de que efectivamente se rechaza la inscripción de la candidatura de Cruz-Coke. Prueba de ello, es que hubo dos requerimientos, de los cuales uno fue formulado por el Partido Socialista y el otro por un candidato competidor en la circunscripción respectiva. Los casos anteriormente citados no fueron patrocinados directamente por partidos políticos, sino por personas naturales aisladas que, si bien pueden ser de relativa influencia política, carecieron en su momento de la representatividad de los intereses del sector. Todo lo contrario, parecía que los políticos en general estaban cómodos con esas decisiones, ya que abrían las puertas a permitir comportamientos similares favorables para ellos en el futuro. Así, por ejemplo, el caso Tohá (que favoreció los intereses del ex gobierno de Bachelet) permitió que el Presidente Piñera pudiera nombrar a ex senadores de la "Alianza por Chile" en su gabinete.

${ }^{10} \mathrm{El}$ artículo 33 sólo dice que deben ser "colaboradores directos e inmediatos" y que deben regularse por ley. No prevé los casos de las figuras híbridas. Si el Presidente del CNCA es un "colaborador directo e inmediato" es discutible, ya que le rinde cuentas a un Consejo y, cuando la ley exija la intervención de un ministro, debe solicitarse la intervención de un sujeto externo al CNCA, quien es, el Ministro de Educación.

${ }^{11}$ La Contraloría General de la República ha estimado que el Presidente del CNCA no es un "ministro" en al menos dos oportunidades, como explicaremos más adelante. Ver Dictamen Contraloría General de la República No 26.261, "Contraloría Regional de Valparaíso con Contraloría General de Chile”, 20 de mayo de 2009 (naturaleza jurídica del cargo del Presidente del Consejo Nacional de la Cultura y las Artes y sus atribuciones). Disponible en: <http://www.contraloria.cl/LegisJuri/DictamenesGeneralesMunicipales.nsf/ FormImpresionDictamen?OpenForm\&UNID=3CF5EA216451EFF9842575C1005C25F0> [consulta: 17 octubre 2013]; y Contraloría General de la República, decreto Rol No 23.200, "Presidente de la República con Contraloría", 4 de mayo de 2010 (toma de razón que cursa decreto "con alcance"). Disponible en: <http://www.contraloria.cl/LegisJuri/DictamenesGeneralesMunicipales.nsf/FrameSetConsultaWebAnonim a?OpenFrameset> [consulta: 17 octubre 2013].

${ }^{12}$ Como se explicará más adelante, el Tribunal Constitucional declaró que el Presidente del CNCA no era ministro. Tribunal Constitucional, Rol No 379, 1 julio 2003 (control de constitucionalidad respecto del proyecto de ley que crea el Consejo Nacional de la Cultura y las Artes y el Fondo Nacional de Desarrollo 
una expectativa fundada de buena fe, como explicaremos en la sección 3 de este comentario. Esta expectativa se vio frustrada debido a que el TRICEL no estaba obligado a seguir la interpretación de la Contraloría y, aunque es discutible si la jurisprudencia del Tribunal Constitucional le es vinculante ${ }^{13}$, el propio TRICEL la ignoró en los hechos.

Por lo anterior, el fallo del TRICEL no debe ser evaluado por el resultado al que arriba, sino por el tipo de fundamentación que utilizó. Estimamos que, atendido el contexto especialmente exigente que describimos en las páginas anteriores, el TRICEL tenía la difícil tarea de construir un argumento coherente y, atendido que su decisión implicaba en los hechos un cambio en el status quo, debía hacerse cargo de la opinión contraria evaluando su mejor versión, y de cuestionarse la mejor respuesta jurídica posible atendidos los valores constitucionales en juego. El TRICEL no podía simplemente ignorar las razones que llevaron a generar la expectativa de que se estaba actuando dentro de las reglas del juego, como efectivamente lo hizo. Por esta razón y otras, en la sección siguiente demostraremos que el fallo del TRICEL adolece de debilidades jurídicas que hacen que pueda, efectivamente, ser considerado como una mala sentencia.

\section{LAS DEBILIDADES DEL FALLO DEL TRICEL}

La sentencia comienza en la parte considerativa descartando de forma "inequívoca" el que Luciano Cruz-Coke haya sido Ministro de Estado: "la cuestión controvertida se reduce a determinar el alcance y efectos de las expresiones 'rango de Ministro de Estado" (considerando 10). En seguida, recurre a la historia del establecimiento de la regla de inhabilidad en el debate de los redactores de la Constitución, incluso citando al comisionado Jaime Guzmán (fundador de uno de los partidos de la "Alianza por Chile") para concluir que el fin de la norma es impedir el aprovechamiento indebido del cargo para obtener una posición política (considerandos $2^{\circ} \mathrm{y}$ 3o). También se determina que el fin de la norma es asegurar que desde el Estado no se alteren las reglas electorales generando condiciones igualitarias entre los competidores, lo que justificaría el impedimento temporal (considerando $4^{\circ}$ ).

Como este argumento utilizado de manera general no admitiría ningún matiz y podría ser aplicado a cualquier autoridad con cierta influencia, no obstante no ser enumerado explícitamente dentro de quienes están sometidos al impedimento

Cultural y las Artes). Disponible en: <http://www.tribunalconstitucional.cl/wp/expedientes> [consulta: 17 octubre 2013].

${ }^{13}$ En efecto, si bien una parte importante de la doctrina sostiene que el Tribunal Constitucional es el intérprete supremo y final de la Constitución, algunos autores cuestionan que este sea el efecto que sus sentencias deban generar. Ver, por ejemplo, Silva IrarrázaVal, Luis Alejandro (2012): “¿Es el Tribunal Constitucional el supremo intérprete de la Constitución?. Revista de Derecho de la Pontificia Universidad Católica de Valparaíso, Vol. 38: pp. 573-616; y Verdugo, Sergio (2013): "La discusión democrática sobre la revisión judicial de las leyes”. Revista Chilena de Derecho, Vol.40, No 1, pp. 181-223. 
temporal, sería maximalista y contrario al sentido de las prohibiciones restrictivas el deducir de él que el Presidente del CNCA está sometido sin un paso lógico adicional. En realidad, este caso trata acerca de una autoridad no explícitamente regulada en la Constitución, por lo que la extensión del listado debería estar sometida a un razonamiento muy riguroso acerca de su calidad de ministro. En otras palabras, el establecer los fines no es un argumento independiente que funcione de manera autosuficiente, ya que necesita de un argumento adicional que, estimamos, el TRICEL falla en entregar.

En efecto, el TRICEL da un salto lógico cuestionable al utilizar sin mayor fundamentación y desarrollo la definición de "rango" del Diccionario de la Real Academia Española - "clase o categoría de una persona con respecto a su situación profesional o social"-, sosteniendo que en "su concreta y real situación profesional - que incluye la representatividad e interlocución igualitaria, en el orden interno con los Ministros de Estado y, externamente, con quienes, en las materias propias del Consejo, ocupan cargos de ese carácter con otros países-... el señor Cruz-Coke ha tenido la clase o categoría de Ministro de Estado, homologación que produce claras e insoslayables consecuencias constitucionales y legales" (considerando $5^{\circ}$ ).

Como únicos fundamentos del ejercicio de potestades de un ministro, utilizan algunas de las razones que categorizamos como lista de lavandería en la sección previa. Así, sostiene que Cruz-Coke firmó dos proyectos de ley y que al asumir sus funciones prestó juramento en calidad de tal (considerando $5^{\circ}$ ). No sólo se trata de dos ejemplos particularmente pobres, sino que ellos no son presentados de forma cabal. En efecto, ellos no se contrastan con otros comportamientos políticos en sentido contrario, siendo desleal con la realidad completa al presentarla de manera parcializada (el clásico problema de los argumentos lista de lavandería) ${ }^{14}$. En general, el fallo pareció derechamente ignorar la lista de lavandería paralela y evitó realizar un razonamiento completo al respecto. Ello era posible, estimamos, incluso defendiendo el resultado al que la sentencia arribaría en definitiva.

Probablemente porque se sabe que esta fundamentación es evidentemente insuficiente, la sentencia acude a ciertos criterios externos novedosos y lejanos a la jurisprudencia del propio TRICEL. Con ello el TRICEL no sólo incrementa la incerteza jurídica de sus decisiones al mostrarse libre de sus propias reglas jurisprudenciales invocadas en el pasado, sino que también quiebra de manera poco justificada una larga tradición en materia de interpretación restrictiva de inhabilidades. Ello no sólo es una regla elemental en el Derecho Público, sino que se deriva de la propia naturaleza de la revisión judicial que realiza este tribunal, que debe ser especialmente deferente con el proceso democrático atendido el impacto que una decisión como esta tiene en los derechos políticos a elegir y ser elegido reconocidos en el capítulo II de la Constitución. Así, el TRICEL sostuvo:

${ }^{14}$ Así, por ejemplo, no se considera que el juramento de ministro fue tomado razón "con alcance" por la Contraloría. Ver Contraloría General de la República, 4 de mayo de 2010. 
"Aun cuando el texto de la norma del artículo $57 N^{\circ} 1$ de la Constitución Política de la República no previno de modo expreso esta situación, teniendo también en consideración que es regla de interpretación constitucional actualmente aceptada recurrir al 'contenido teleológico de la Constitución' (en este sentido TC Rol 352-2001), ha de concluirse que al señor Cruz-Coke le afecta la inhabilidad solicitada, puesto que con este entendimiento de la norma, ante la misma situación fáctica que se tuvo en cuenta para incorporarla al texto constitucional también se hace aplicación de la garantía de igualdad ante la ley, cuyo aseguramiento importa el objetivo esencial de la misma y el motivo de reclamo de los impugnantes" (considerando 60).

La fuente citada por el TRICEL admite varias críticas. Primero (i), se relaciona bastante poco con el caso en cuestión (el caso interpreta las facultades de los parlamentarios para impugnar un decreto); segundo (ii), se asume que las sentencias del Tribunal Constitucional pueden servir de base para la fundamentación de una sentencia del TRICEL, aunque sea como fuente meramente persuasiva y no directamente vinculante; tercero (iii), se desconoce la jurisprudencia (incluyendo la del propio Tribunal Constitucional) que revisa con ánimo especialmente restrictivo el problema de las inhabilidades y prohibiciones y que incluso hace equivalente la naturaleza del Presidente del CNCA a la de un jefe de servicio ${ }^{15}$; y cuarto (iv) con lo anterior queda en evidencia un uso selectivo del elemento interpretativo llamado teleológico por parte del TRICEL y de las fuentes elegidas para fundar su decisión. De esta manera, la decisión puede ser fácilmente reprochada.

La argumentación del TRICEL es formalista, ya que interpreta las palabras relevantes sobre la base de un supuesto fin normativo presente en las actas de la Comisión de Estudios, ignorando otras consideraciones constitucionales significativas para la determinación de los valores atingentes al caso. Utilizar la historia de la Constitución para solucionar un problema que el constituyente no previó (como es el caso de estas figuras híbridas) es no ser leal con las técnicas de interpretación constitucional, incluso si se es originalista. Es más, la sentencia utiliza las actas de forma acrítica pese a toda la doctrina existente que advierte acerca de limitaciones ${ }^{16}$ para algo que no debía hacer: interpretar la naturaleza de la institución de acuerdo a la historia de una norma que no creó dicha institución. En efecto, si el TRICEL hubiese querido analizar especialmente la naturaleza verdadera de esa institución, debiera lógicamente recurrir a la historia de la misma, contenida en su propia ley,

\footnotetext{
${ }^{15}$ Tribunal Constitucional, 1 julio 2003.

16 Por ejemplo, ver: Zapata Larraín, Patricio (2008). Justicia Constitucional. Teoría y Práctica en el Derecho Chileno y Comparado. Santiago: Editorial Jurídica de Chile, pp. 189-196; VIal Solar, Tomás (2002). "La Ilegitimidad de la Historia Fidedigna de la Constitución de 1980". Revista de Derecho, Universidad de Concepción, Vol. 212, pp. 317-328; FigueroA, Rodrigo (2000). "De por qué no debemos prestar tanta atención al argumento genético en la interpretación constitucional”. Revista de Ciencias Sociales, No 45, pp. 587-603.
} 
cuestión que eludió hacer ${ }^{17}$. Nadie le pide al TRICEL que sea originalista, pero si decide serlo, al menos debe ser riguroso ${ }^{18}$.

Por otro lado, si el TRICEL en realidad quiere hacer un análisis teleológico desde la Constitución, no puede ignorar la existencia de profundos y evidentes valores constitucionales en juego que están siendo afectados por el caso. No sólo la democracia y el ejercicio de la soberanía se reducen, sino que los derechos políticos de los ciudadanos de la circunscripción respectiva y el derecho a presentarse a cargos públicos se ven afectados. ¿Carecen ellos de toda relevancia jurídica? EL TRICEL, a lo menos, debió hacerse cargo de analizar la manera en que se pueden acomodar todos estos valores constitucionales, pero en vez de eso decidió ignorarlos sosteniendo al mismo tiempo una supuesta "interpretación teleológica". Una explicación para esta contradicción es el posible uso selectivo de fuentes citadas.

En este mismo sentido, debe considerarse que el abandono de las técnicas restrictivas de interpretación hace sufrir enormes costos al sistema. No sólo se afecta la certeza jurídica de las prohibiciones, sino que se abre la puerta a la existencia de sanciones contra conductas que se estimaron legítimas atendido el marco jurídico disponible. Con ello, se fortalece la asimetría de información que a veces poseen los sistemas jurídicos en sus siempre existentes "vacíos" o loopholes, y se reduce el espacio de la deferencia democrática que los jueces deben guardar por la actividad propiamente política. Por eso, sostener una doctrina como la del TRICEL en casos de naturaleza diversa, podría traer consecuencias insospechadamente perjudiciales para nuestro sistema. Ello hace que, si bien esta decisión pueda actuar como precedente limitando la incerteza futura respecto de las posibilidades de presentarse como candidato a parlamentario de un Presidente del CNCA, ella genera incertidumbre en otras controversias que en el pasado han sido solucionadas bajo doctrinas opuestas; incrementando de manera poco predecible el poder de revisión judicial.

\section{El problema de la justicia del Caso y las consecuencias (IR)RELEVANTES (IN)ADVERTIDAS}

Sin perjuicio de que, y como adelantamos en la sección 1, la solución jurídica del problema era relativamente impredecible, ello no significa que la inscripción de la candidatura hubiese sido efectuada de manera jurídicamente imprudente. En efecto, el ex candidato Cruz-Coke tenía una expectativa justificada de no haber sido ministro para los efectos de presentarse válidamente como candidato a senador

\footnotetext{
${ }^{17} \mathrm{El}$ informe en Derecho del profesor Eduardo Soto Kloss, acompañado al proceso, era particularmente ilustrativo en este punto.

18 Sobre los problemas interpretativos originalistas, aplicados al caso de Cruz-Coke, hemos escrito otro trabajo que puede consultarse. Ver Verdugo, Sergio y García, José Francisco (2013), "Como (mal) usar la técnica originalista de interpretación. A propósito del caso de Luciano Cruz-Coke”, en prensa.
} 
pese a no cumplir con el plazo de un año en su renuncia previa. Esta expectativa, que llevó a Evópoli y a Renovación Nacional a apoyar la candidatura y a darle un espacio en la lista cerrada de la "Alianza", estaba fundada en dos razones fundamentales: en primer lugar (i), la inexistencia de interpretaciones de autoridades que estimaran que si era ministro (no había jurisprudencia judicial ni administrativa, ni doctrina jurídica en ese sentido); y, en segundo lugar (ii), la existencia efectiva de interpretaciones de la Constitución que sostenían que su cargo no era el de un ministro verdadero (en los términos constitucionales).

Este segundo motivo fundante de la expectativa constó no sólo en informes en Derecho de respetados académicos de Derecho Público chileno ${ }^{19}$, sino también en la opinión de instituciones relevantes para el Derecho Constitucional: la Contraloría General de la República y el Tribunal Constitucional ${ }^{20}$. Ante la ausencia de jurisprudencia del TRICEL en la materia, las señales jurídicas de estas dos instituciones colaboraron a formar la expectativa que condicionó el comportamiento de los actores políticos involucrados y cuya doctrina fue aceptada por el SERVEL en la inscripción de la candidatura ${ }^{21}$.

La Contraloría había determinado que el Presidente del CNCA era un "jefe superior" que "posee la calidad de funcionario público", y que ello no obstaba a que la ley haya querido reforzar su "representatividad e interlocución igualitaria, en el orden interno, con los ministros (...)”. En este mismo dictamen, la Contraloría constató que a este funcionario "no le asisten atribuciones propias de los Ministros de Esta-

\footnotetext{
${ }^{19}$ En el proceso, se tuvo a la vista dos informes en Derecho que defendían la posición de Cruz-Coke. Se trató de los muy conocidos y respetados profesores Mario Verdugo Marinkovic (Universidad de Chile) y Eduardo Soto Kloss (Pontificia Universidad Católica de Chile). Cabe hacer presente que los reclamantes del proceso también presentaron un informe en Derecho que defendió la posición contraria. Se trató del profesor Mario Quinzio Figuereido (Universidad de Chile).

${ }^{20}$ También podría agregarse la propia resolución del Servicio Electoral (“SERVEL”), que acepta la inscripción de la candidatura. Consejo Directivo del SERVEL, 28 de agosto de 2013, Resolución O-10.701, (inscripción candidatura), Diario Oficial, No 39.654, p. 4. Esta resolución no la agregamos a la lista de autoridades que entendieron que el Presidente del CNCA no era un verdadero ministro, ya que justamente éste es el acto administrativo que resulta impugnado por las dos reclamaciones que conoció el TRICEL en su proceso.

${ }^{21}$ Cabe hacer presente que también ha habido casos vinculados al gobierno precedente (el de Bachelet) donde se ha seguido la interpretación de que el Presidente del CNCA no es un verdadero ministro. Como da cuenta el profesor Eduardo Cordero, "en el año 2008 el gobierno de la ex Presidenta Michel Bachelet enfrentaba una de las crisis más graves de su gestión con la implementación del sistema de transporte (...), siendo una de sus aristas más delicadas la falta de financiamiento (...). Fue así como se tomó la decisión de dictar un Decreto de Emergencia Constitucional (...) dicho decreto debía ser firmado por todos los Ministros de Estado (...). En la ocasión concurrieron de forma muy disciplinada todos los Ministros de Estado al Palacio de La Moneda, incluyendo cuatro jefes de servicios con "rango" de Ministro de Estado (en aquella ocasión SERNAM, CONAMA, Consejo Nacional de la Cultura y las Artes y la Comisión Nacional de Energía). Sin embargo, a los pocos minutos estos últimos debieron emprender retirada, ya que se les dijo que no tenían la calidad de Ministros y que no debían firmar, criterio confirmado posteriormente por la Contraloría General de la República que tomó razón del decreto". Ver la opinión del profesor Cordero QuinZACARA (2013).
} 
$d o(\ldots)$ "22. Por su parte, en un control preventivo de constitucionalidad, el Tribunal Constitucional había declarado con anterioridad que el Presidente del CNCA no era ministro y que, por consiguiente, no debía suscribir el decreto supremo que contenía un reglamento (función exclusiva de los ministros-artículo 36 de la Constitución-). Por esta razón, el Tribunal Constitucional declaró inconstitucional un precepto legal que requería su firma, bastando para ello la firma del Presidente de la República y de los ministros respectivos (Hacienda y Educación)23.

Estos antecedentes, si bien pueden generar discusión en el sentido de que no obligan directamente al TRICEL (un órgano constitucional autónomo que tiene capacidad para interpretar directamente la Constitución), habían formado una expectativa legítima en el ex candidato, cuyo sector político, de buena fe, interpretó la regulación vigente como permisiva con la candidatura. Si a ello se sumaban los argumentos favorables a los derechos políticos, entonces había buenas razones para tener tranquilidad en el asunto, estimando que la decisión de competir e inscribir la candidatura no era judicialmente riesgosa. Si hubiese habido una duda mayor al respecto, es muy probable que, en definitiva, los actores políticos relevantes (en especial el partido Renovación Nacional y el movimiento político Evópoli) hubieran inscrito a otro candidato, o el propio Cruz-Coke hubiera renunciado en el plazo correspondiente.

Estas consideraciones no son, en efecto, suficientes como para estimar que el resultado del fallo fue erróneo. Sin embargo, son suficientemente relevantes como para haber exigido al TRICEL que hubiera ejercido su función con una especial prudencia, sobre todo en su argumentación. Cualquier decisión judicial contraria a lo estimado tanto por la Contraloría como por el Tribunal Constitucional (como efectivamente sucedió) significaría, en la práctica, la aplicación retroactiva de una nueva regla jurídica con el consiguiente cambio normativo, impidiendo o perturbando con ello el ejercicio de derechos constitucionales, en especial los derechos políticos del capítulo II de la Constitución ${ }^{24}$. Con su sentencia, el TRICEL afectó la seguridad jurídica provocando las graves consecuencias políticas que se mencionaron en la introducción. En este escenario, debiéramos preguntarnos si su resultado (no su doctrina) fue efectivamente equitativo para el caso y saludable para el sistema. Si se estimara que la doctrina del TRICEL es la correcta, debiéramos

\footnotetext{
${ }^{22}$ Contraloría General de la República, 20 mayo 2009. En un sentido similar, aunque tal vez menos evidente, cuando el Presidente Piñera nombró a los ministros respectivos al comienzo de su gobierno, dictó un decreto de nombramiento que fue tomado razón "con alcance" por parte de la Contraloría General de la República. En esa oportunidad, el Contralor estimó "necesario precisar que las designaciones (...) de don Luciano Cruz-Coke Carvallo en el Consejo Nacional de la Cultura y las Artes (...) han sido efectuadas con rango de Ministro de Estado". Contraloría General, 4 mayo 2010.

${ }^{23}$ Tribunal Constitucional, 1 julio 2003.

${ }^{24}$ Aquí se aplica la observación citada al comienzo, donde Martin Shapiro sostiene que cuando los jueces crean normas, sus sentencias producen efectos retroactivos y, cuando argumentan que no son nuevas normas, entonces ineludiblemente su función consistirá en la mentira. Ver SHAPIRO (1994).
} 
cuestionarnos si no hubiese sido mejor que la nueva regla comenzara a regir sólo para lo futuro, promoviendo con ello el establecimiento de seguridad jurídica y no dañando la misma. Con la misma doctrina, el TRICEL pudo haber eludido los defectos de su decisión manteniendo su interpretación de la ley, mediante el establecimiento de un ejercicio hermenéutico acomodaticio de los valores constitucionales en juego.

Si bien una salida como ésta probablemente generaría críticas relativas al rol de los jueces y a su capacidad para regular los efectos de sus sentencias, creemos que en situaciones como ésta, donde los magistrados están llamados a generar reglas nuevas que pueden implicar un cambio normativo, la única solución equitativa y certera que posibilitara combinar la interpretación constitucional del TRICEL con evitar los daños causados, es la que describimos. Este tipo de ejercicio no es nuevo en el derecho chileno. Prueba de ello lo representa un dictamen de la Contraloría General de la República en otro tipo de casos, donde se estima que los cambios de criterio, o los criterios nuevos de conductas pasadas, deben operar hacia el futuro 25 .

Por supuesto, este tipo de decisión no habría sido necesaria si el TRICEL hubiere seguido la doctrina del voto de minoría y hubiera, sencillamente, argumentado de acuerdo a la doctrina correcta.

\section{CONCLUSiOnes}

El caso sobre la prohibición de Luciano Cruz-Coke para ser candidato a senador será recordado por varias razones. Por un lado (i), la sentencia significó la primera respuesta jurídica directa a este problema por parte del TRICEL, con lo que probablemente condicionará el comportamiento del SERVEL y de los candidatos en el futuro, haciendo que el Presidente del CNCA tenga que renunciar un año antes de las elecciones parlamentarias. Por otro lado (ii), el fallo implicó un cambio normativo sustancial tanto en el tratamiento jurídico del Presidente del CNCA como en la doctrina restrictiva de las prohibiciones en materia de Derecho Público, con lo que podría afirmarse que el TRICEL se separa, en este punto, de su pasado y de la jurisprudencia de otras instituciones relevantes como la Contraloría General de la República y el Tribunal Constitucional (los que no están vinculados por la doctrina del TRICEL). Ello podría producir un relativo escenario de incertidumbre en el futuro.

Sin perjuicio de estos dos naturales efectos por los cuales la sentencia del caso Cruz-Coke será recordada, mediante este comentario hemos intentado formular una crítica al TRICEL, ya que estimamos que esta decisión judicial es demostrativa de una de las maneras menos afortunadas de resolver este tipo de causas. Hemos

${ }^{25}$ Ver Dictamen Contraloría General de la República No 73040, "Sobre intervención electoral en que habrían incurrido Ministros de Estado. Reconsidera toda jurisprudencia en contrario”, 31 de diciembre de 2009. 
demostrado que ella lesiona la buena fe y la certeza jurídica, introduciendo un cambio normativo con efecto retroactivo con grandes consecuencias para los derechos políticos involucrados. También, hemos evidenciado razones por las cuales esta sentencia hace sospechar acerca de un posible uso selectivo de las fuentes que cita, tanto en sus antecedentes (como ocurre con la cita a la jurisprudencia del Tribunal Constitucional) como en sus elementos de interpretación; lo cual ha llevado al TRICEL a ser excesivamente formalista en una decisión que requería del análisis de valores constitucionales en juego de especial importancia.

La crítica que formulamos es probablemente compatible con la doctrina final del fallo (aunque no con sus efectos, desde luego), pero no con su argumentación, la que estimamos especialmente pobre y parcializada. Por ello, creemos que el uso de la lista de lavandería como estrategia argumentativa, ha conducido a un escenario muy limitado de discusión jurídica que no se concilia con el propio rol de los jueces al enfrentarse a este tipo de controversias. 